\title{
Consolidation Simulation of Highly Viscous Dredger Fill in Different Vacuum Preloading Process
}

\author{
LIU Zhiqing ${ }^{1, a}$, ZHANG Peng ${ }^{2, b^{*}}$ \\ ${ }^{1}$ School of Earth Sciences and Geological Engineering, Sun yat-sen University, Guangzhou \\ 510275 , China \\ ${ }^{2}$ CCCC-FHDI Engineering co., Ltd., Guangzhou 510230 , China \\ aeasky@126.com, ${ }^{b}$ zhp20120619@126.com, * Corresponding author.
}

\begin{abstract}
Keywords: Highly viscous dredger fill, Graded vacuum preloading, Particle flow code in three dimensions, Consolidation

Abstract: A numerical simulation model based on the particle size composition of High Viscous Dredger Fill (HVDF) was established. Consolidation process of HVDF was in the action of Direct Drainage Vacuum Preloading (DDVP) and was in the Graded Vacuum Preloading (GVP), which was described the drainage consolidation characteristics of HVDF subject to the two drainage systems. The two methods of preloading were compared with different distance between two drainage boards. Both DDVP and GVP improved vacuum preloading velocity. But GVP was advantageous over DDVP in HVDF consolidation. The porosity of HVDF gradually become uniform in GVP. And it is suitable for HVDF consolidation to distribute probable time ratio and vacuum degree escaped from silting-up. So the laboratory experiments based on the results of numerical simulation explored the mechanisms of HVDF consolidation under GVP.
\end{abstract}

\section{Introduction}

High Viscous Dredger Fill (HVDF) have been widely used in engineering foundation treatment in the coastal field[1,2], to solve the issues of creep problems, the deformation, and strength of drainage consolidation[3,4]. Recent research has shown that the efficiency of consolidation could be improved by adjusting drainage velocity in the existing pore network[5,6]. Soft soils with clay, rationally, may have more paths to enhance capillary transport.

During the dredger fill sedimentation, single particles flow separately, which were similar to hydrostatic sedimentation and were approximately described by the Stokes' sedimentation theory[7]. However, consolidation velocity of dredger fill was slowly that influenced engineering efficiency.

Based on the particle size composition of dredger fill with high viscous particle content and the engineering characteristics of the consolidation drainage, a numerical simulation model was established under the action of Direct Drainage Vacuum Preloading (DDVP) and Graded Vacuum Preloading (GVP). The drainage consolidation characteristics of HVDF were subjected to the two drainage systems, and were compared with effects of the distances between two drainage boards.

\section{Laboratory experiments}

Before Laboratory experiment, physical characteristics were tested. The diameter distribution of the dredger fill from Daya Bay was measured by Hydrometer Grain analysis and sodium hexametaphosphate shown as Table 1. Most of particles were Silt and Viscous particles, while a little bit of particles over $0.075 \mathrm{~mm}$ were in $2.33 \%$, suggesting that the dredger fill can be classified to High Viscous Dredger Fill (HVDF). The plasticity index of HVDF was 23. X-Ray Diffraction analysis indicated that the minerals in the clay include kaolinite, illite, and illite smectite. Besides, original minerals of quartz, feldspar, and muscovite were also found. The other properties of the clay include high water content of $80 \mathrm{wt} \%$, large pore ratio of 1.2 , with low shear strength of $3 \mathrm{kPa}$ and cohesion 
force of $5^{\circ}$ internal friction, poor permeability coefficient of $10^{-8} \mathrm{~cm} / \mathrm{s}$, and sensitivity microstructure of granule-flocculent structures.

Table 1 Components of dredger fill

\begin{tabular}{ccccc}
\hline Fraction name & Sand $(\mathrm{mm})$ & Silt $(\mathrm{mm})$ & Viscous particles $(\mathrm{mm})$ & Quantity \\
Range & $>0.075 \mathrm{~mm}$ & $0.075 \sim 0.005$ & $0.005 \sim 0.002$ & \\
Mass fraction & $2.33 \%$ & $67.25 \%$ & $30.42 \%$ & $100 \%$ \\
\hline
\end{tabular}

And the Fig.1 shows the schematic of laboratory experiments. The experimental process is illustrated as follows: 1) Inject uniformly stirred dredger fill into the test chamber of $0.5 \mathrm{~m} \times 0.5 \mathrm{~m} \times 0.5 \mathrm{~m}$; 2) Insert one end of a $0.6 \mathrm{~m}$ long drainage board to the bottom of the chamber and locate the other end on the surface of dredger fill; 3 ) Use the drain pipe as a guide to lead the sand bag to the bottom of the model box, thus forming a sand bag well; 4) Coat the surface of dredger fill with a film; 5) Directly connect the drainage body with the drainage pipe, that in turn links to the vacuum device; 6) Switch on the vacuum device for trial pump to check both the vacuum pumping efficiency and the sealing performance of the model; 7) Start vacuum pumping after the vacuum degree reaches $85 \mathrm{kPa}$.

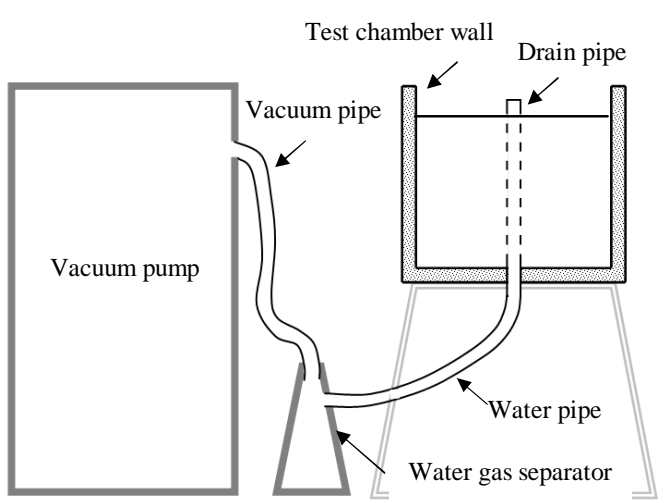

(a) Test chamber composed of side view

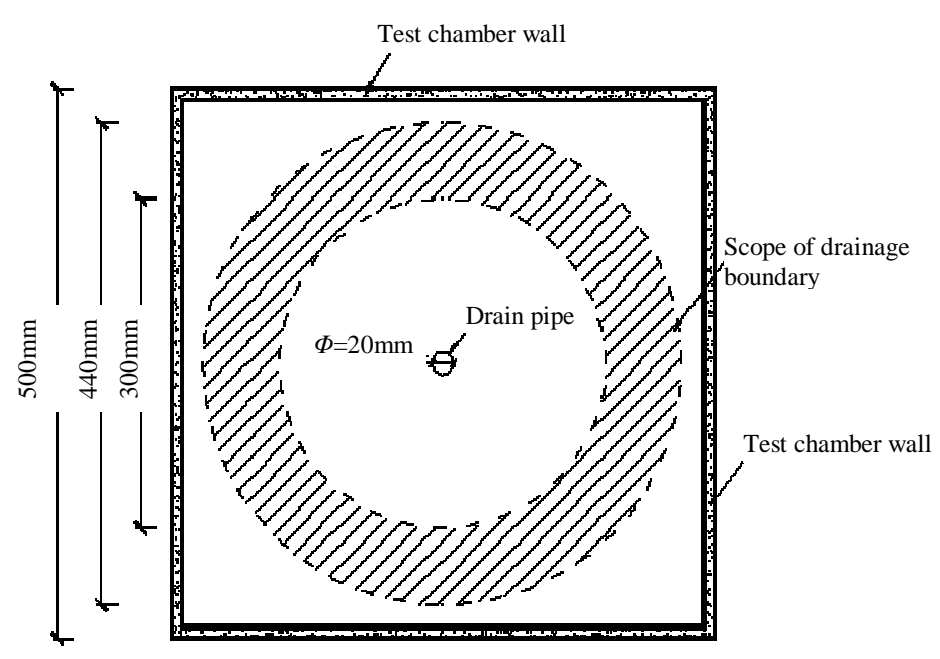

(b) Test chamber composed of top view

Fig.1 The apparatus of HVDF consolidation test

DDVP refers to the process that dredger fill was blown into the construction site. In order to solve HVDF silting-up, Wang Qing put forward the concept of GVP in 2006. She believed that fine particles of HVDF subject to GVP action will reduce migration. Thus, the experiment was designed to confirm the concept so as to improve the consolidation efficiency of HVDF. Because GVP was adopted to consolidate in the experiment, some auxiliary devices including the graduated cylinder, plastic film, and water collector were needed to measure the volume of drainage and keep the vacuum degree in the dredger fill.

\section{Numerical model establishment conditions}

During the testing processes of both DDVP and GVP, the consolidation of dredger fill occurs under the action of vacuum suction at the drainage body center. A preliminary simplified numerical model was put forward in 3-D rectangular solid.

Viscous particles in dredger fill at this time have been actually formed into "fake silt" aggregates. In addition, according to a previous study, the growth in soil strength was closely related to the content of "fake silts". And the side length of the rectangular body built up in the numerical model should be greater than $0.09 \mathrm{~mm}$. In Fig.2, soil particles were subjected to both self-weight and vacuum 
preloading. The distance between two drainage boards (as distance of $\mathrm{CD}$ ) was set as $\mathrm{L}, 1.5 \mathrm{~L}$, and $2 \mathrm{~L}$, respectively. The mesh drainage boards with their mesh length of $0.005 \mathrm{~mm}$ were set up separately on the right and left sides of soil. White particles in soil were silts with size between $0.02 \mathrm{~mm}$ and $0.01 \mathrm{~mm}$; green and yellow particles were clay particles with size between $0.005 \mathrm{~mm}$ and $0.002 \mathrm{~mm}$. With consolidation going on, the soil strength increases continuously. The fluid-solid coupling analysis was carried out in the soil's initial state. Its bilateral drainage bodies were in vacuum degree of $80 \mathrm{kPa}$ and the soil was subjected to the vacuum force moves toward its left and right sides.
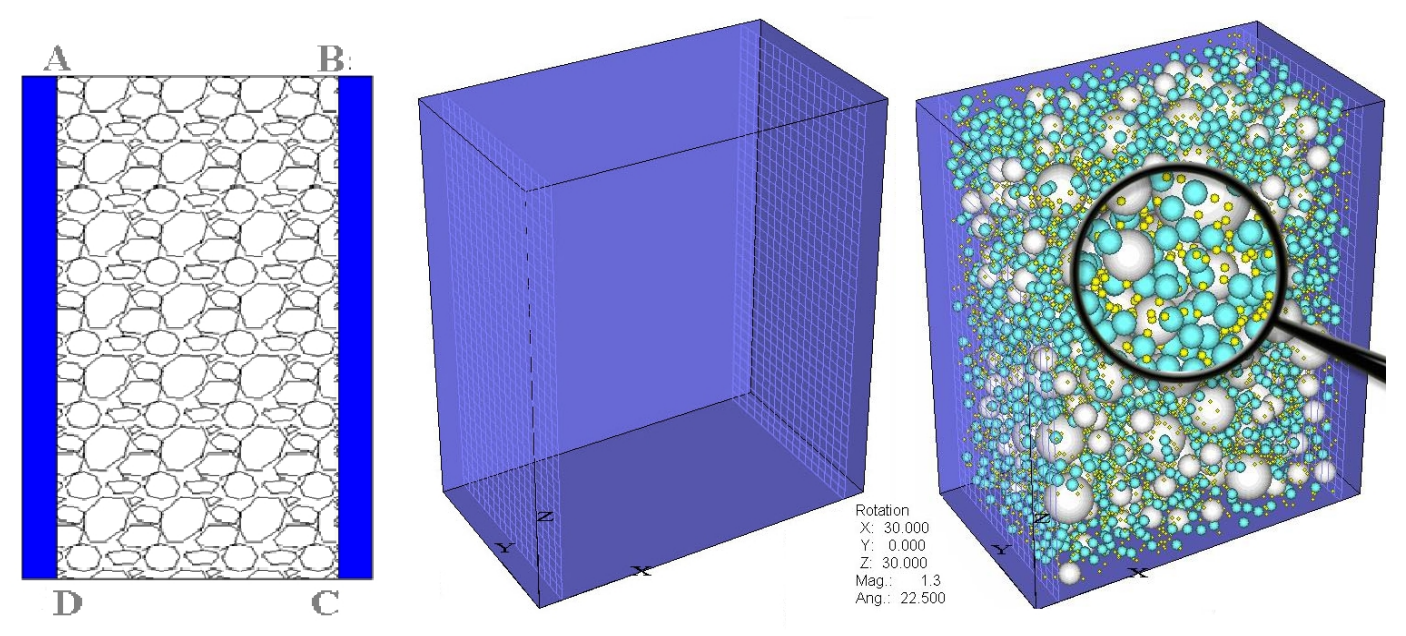

Fig.2 Simulation of particles and pores in 3D

The bilateral walls played both roles to block large particles. All particles on which perform their force-displacement operations, which consumes a lot of computing time, so it is more efficient using the mesh wall. The specification of the B-type board with the equivalent aperture $\leq 75 \mu \mathrm{m}$ is referred for the size of the particle wall in this simulation process. The mesh wall with mesh side length of $0.005 \mathrm{~mm}$ meets the conditions as the filter layer and was utilized to simulate the ideal dredger fill consolidation process.

\section{Numerical analysis of DDVP}

DDVP based on HVDF consolidation was shown as Fig.3 in different drainage conditions. The stress between particles in the initial stage was small. The stress state of soil was represented mainly by the force between particles and their surrounding wall body.

The arrangement of particles at 1000 steps shows a loose structure. The degree of vacuum occurs in the whole soil acted by their own weight. In addition, suffering the horizontal vacuum suction, fine particles on the surface layer sunk slowly. The yellow particles continuously passed through the drainage boards into the drainage body in which they congregate in abundance. At 2000 steps, fine particles on the surface layer gradually sunk. Thus soil particles suffer from relatively smaller horizontal vacuum suction. The soil at the intermediate position between two drainage bodies was subjected to the horizontal vacuum suctions on left and right sides, causing particles to be suspended with lowering porosity. At 3000 steps, with drainage board space increasing, the amount of soil subsidence gradually increased. More and more fine particles gathered near the drainage boards to silting-up.

During soil consolidation, the soil porosity first decreases and then increases. The porosity of the upper soil was greater, while the porosity of the lower soil gradually decreases. The dredger fill at the bottom closed to the left side of drainage body had the minimum porosity of 0.35 and average porosity of 0.45 , while the dredger fill at the top close to the right side of drainage body had the maximum porosity of 0.95 and average porosity of 0.90 . It is obvious that DDPV starting moment was too early. Thus, particles could not timely form a stable structure, leading to the loss of a large number of fine 
particles and a waste of soil material. For HVDF, it was suggested firstly use lower vacuum preloading to reinforce dredger fill.

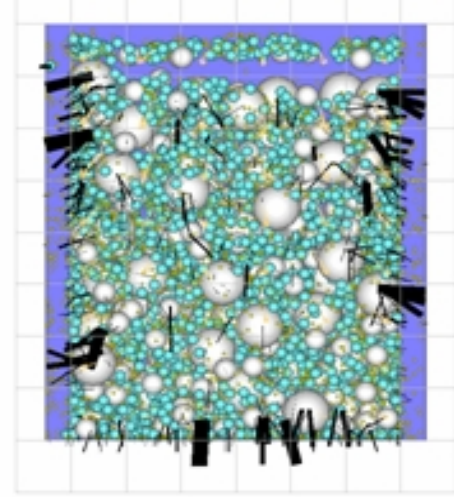

(a) 1000 steps

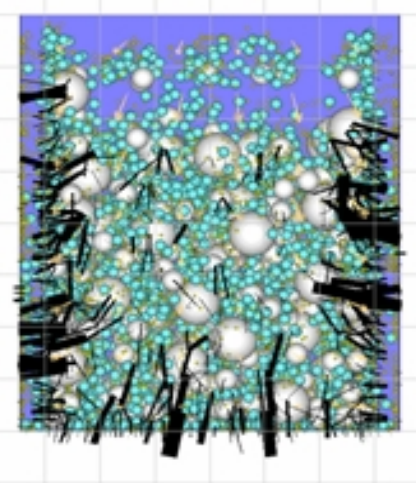

(b) 2000 steps

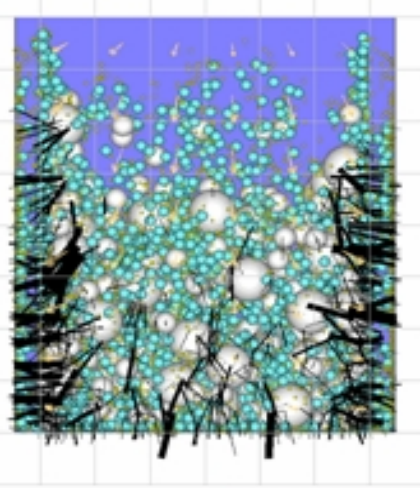

(c) 3000 steps

Fig.3 Porosity of HVDF in DDVP

\section{Discussion with GVP and DDVP}

The numerical model for GVP was partially the same as DDVP except their boundary conditions in which the vacuum degrees was set at $0 \mathrm{kPa}, 10 \mathrm{kPa}, 20 \mathrm{kPa}, 40 \mathrm{kPa}$, and $80 \mathrm{kPa}$ shown as Fig.4. The duration for porosity changed from non-uniform to uniform between 5000 and 10,000 steps. This period was preliminarily judged to be the transition point of self-weight silting-up. At the moment, HVDF with higher porosity was found in the vicinity of the drain pipe, while HVDF with lower porosity in the middle of two pipes.

The change in the porosity of soil body is monitored through numerical simulation experiments. After GVP, the porosity of lower soil body gradually reduced in the consolidation process with minimum porosity of 0.23 at the bottom of the dredger fill, as well as average porosity of 0.25 . Self-weight silting-up process as well as GVP process made HVDF consolidate better. In order to obtain best consolidation status, the time ratio of each vacuum preloading step was settled to be 10: 10: 4: 2: 1 . With the consolidation time increasing, soil porosity gradually became uniform. The duration was preliminarily judged to be the transition point of the self-weight silting-up. At the moment HVDF in the vicinity of the drainage body had higher porosity, while HVDF was far away from the drainage body had smaller porosity, which was favorable for vacuum degree transfer.

Once the self-weight silting-up stop, the wastage of viscous particles through the drainage board under the GVP obviously reduce. The above research also indicates that both DDVP and GVP were improved vacuum preloading. However, the latter was much better for HVDF for its gradually increasing seepage channels in the soil more easily.

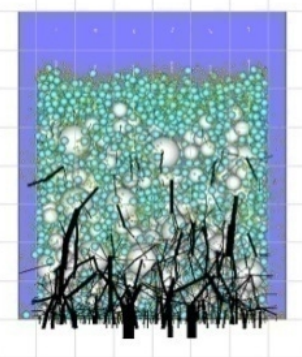

(a) Selfweight $\rightarrow \rightarrow \rightarrow \rightarrow$

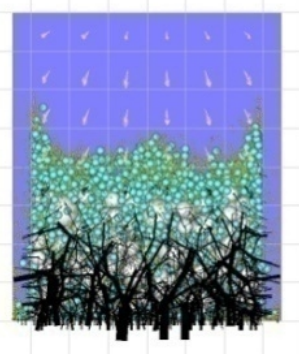

(b) $10 \mathrm{kPa} \rightarrow \rightarrow \rightarrow \rightarrow \rightarrow$

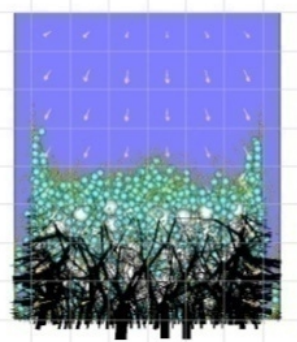

(c) $20 \mathrm{kPa} \rightarrow \rightarrow \rightarrow \rightarrow \rightarrow$
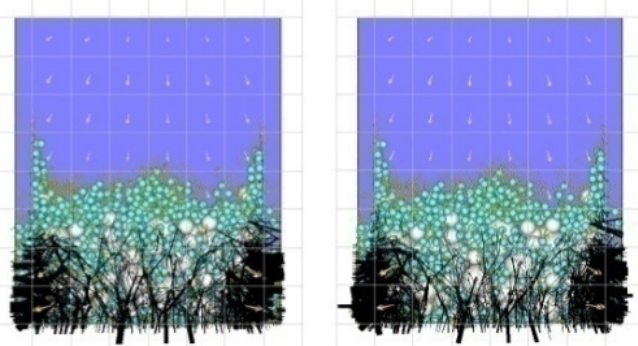

(d) $40 \mathrm{kPa} \rightarrow \rightarrow \rightarrow \rightarrow \rightarrow$ (e) $80 \mathrm{kPa}$

Fig.4 Porosity of HVDF in GVP 


\section{Conclusions and suggestions}

The sample of HVDF was obtained from engineering project with special characteristics. Through establishment of vacuum preloading models and numerical simulations of DDVP and GVP, there are several results and suggestions concluded as follows.

HVDF under GVP has better porosity distribution and increased consolidation. In spite of DDVP's fast consolidation, it is prone to silting-up. The GVP could effectively reinforce HVDF after a period of self-weight. In HVDF consolidation process, silting-up does not occur in the vicinity of the drainage board. With the consolidation time increasing, the distribution of soil porosity gradually becomes more uniform.

As a result, it is suggested to consolidate HVDF in GVP after self-weight silting-up from lower vacuum degree. For example, the vacuum degree could be from $10 \mathrm{kPa}$ gradually increasing to $20 \mathrm{kPa}$, to $40 \mathrm{kPa}$, and then to $80 \mathrm{kPa}$. And it is suitable for HVDF consolidation to distribute time ratio as 10:10:4:2:1 escaped from silting-up.

\section{Acknowledgements}

This work was financially supported by National Natural Science Foundation of China (41402239), Natural Science Foundation of Guangdong Province China (S2012040007331), the Foundation for Distinguished Young Talents in Higher Education of Guangdong, China (2012LYM_0007), and the Foundation for Young Teacher by the Ministry of Sun Yat-sen University (13lgpy63).

\section{References}

[1] Horpibulsuk, S., Miura, N., Koga, H., Nagaraj, T.S.. Analysis and strength development in deep mixing: a field study. Ground Improvement. Vol.8(2), (2004), p.59-68.

[2] Li, F., Han, J., Lin, C.. Effect of Scour on the Behavior of Laterally Loaded Single Piles in Marine Clay. Marine Georesources \&Geotechnology. Vol.31(3), (2013), p.271-289.

[3] Roscoe, K.H., Burlan, J.B., in: On the generalized stress-strain behavior of wet clays. In Engineering Plasticity, Edited by J. V. Hayman and F. A. Leckie/Cambridge University Press, England, (1968), p.535-609.

[4] Murad, M.A., Cushman, J.H.. Thermomechanical theories for swelling porous media with microstructure. International Journal of Engineering Science. Vol.38(5), (2000), p.517-564.

[5] Song, J., Tang, L.S., Xing, R.J.. Anisotropic variation characteristics of pore distribution based on saturated clay microstructure. Applied Mechanics and Materials, Advances in Civil and Industrial Engineering. Vol.353-354, (2013), p.1203-1206.

[6] Ouhadi, V.R., Yong, R.N., Rafiee, F.. Impact of carbonate and heavy metals on micro-structural variations of clayey soils. Applied Clay Science. Vol.52(3), (2011), p.228-234.

[7] Song, J.. Laboratory simulation test and PFC3D numerical analysis of high clay dredger fill in the consolidation process of step-vacuum-preloading, $\mathrm{PhD}$ dissertation, Jilin University, China, (2011). 